\title{
The relationship between deliberate self-harm behavior, body dissatisfaction, and suicide in adolescents: current concepts
}

This article was published in the following Dove Press journal:

Journal of Multidisciplinary Healthcare

28 May $201 \mathrm{I}$

Number of times this article has been viewed

\section{Donald E Greydanus ${ }^{1,2}$ Roger W Apple ${ }^{3}$}

'Pediatrics and Human Development; College of Human Medicine, Michigan State University, East Lansing, MI, USA $;{ }^{2}$ Kalamazoo Center for Medical Studies, Michigan State University, Kalamazoo, MI, USA; ${ }^{3}$ Psychological Evaluation and Consultation Services, Kalamazoo Regional Educational Service Agency, Portage, MI, USA
Correspondence: Roger W Apple Psychological Evaluation and Consultation Services, Kalamazoo Regional Educational Service Agency, I819 Milham Road, Portage, MI 49002, USA

Tel + I 2692509327

Fax +I 2692509322

Email rapple@kresa.org
Abstract: Deliberate self-harm (DSH) is a common though often hidden condition in children and adolescents that may result in suicide. This discussion covers several aspects of DSH including its prevalence, etiology, and management. The relationships of DSH to body dissatisfaction and suicide are specifically considered. Even though most cases of DSH do not end in overt suicide, DSH reflects that potential underlying psychological pathophysiology, and likelihood of eventual death from self-murder, cannot always be predicted or prevented. It is important to take all acts of DSH as serious, and to offer comprehensive management to prevent future acts of DSH and potential suicide.

Keywords: deliberate self-harm, body dissatisfaction, suicide risk, children, adolescents, etiology, management

\section{Introduction}

Deliberate self-harm (DSH) refers to an act of purposefully harming oneself physically that may or may not reflect a real suicidal intent. ${ }^{1}$ The most common methods of DSH are overdosing, self-poisoning, and self-cutting; Table 1 lists various DSH methods that have been noted by clinicians. ${ }^{1-3}$ While adolescents and young adults may use any of the methods listed in Table 1, children typically utilize such methods as self-biting or self-scratching. Risk of specific suicide increases considerably in those expressing a strong intent of death, using a highly lethal method (such as a gun), taking clandestine means to prevent detection, and/or having underlying, untreated psychiatric disorders. ${ }^{1,3}$ DSH in those with intellectual disability (ID) involves head banging, skin-picking, eye gouging, and other self-mutilation behavior.

\section{DSH prevalence}

Table 2 lists recent studies from a number of countries that provide a picture of current DSH prevalence rates. ${ }^{2-11}$ DSH is also noted in individuals of all ages with ID; however, such behavior can be difficult to predict and understand. ${ }^{12}$ Some estimate the prevalence of nonsuicidal self-injury (NSSI) among adolescents as ranging from $13 \%-23 \%$, with these numbers unfortunately increasing. ${ }^{13}$ One report on those with ID noted DSH in $10 \%$ of children and adolescents over a lifespan, ${ }^{14}$ while others report a range up to $41 \% .{ }^{15} \mathrm{DSH}$ is more common in females than males and often involves substance abuse, depression, anxiety, impulsivity, low self-esteem, and recent self-harm by family members. ${ }^{16}$ 
Table I Self-harm methods'

I. Battery (self-hitting)
2. Biting
3. Drug overdose
4. Hanging
5. Jumping from high places (ie, buildings, bridges, others)
6. Pinching
7. Scratching
8. Self-burning
9. Self-cutting
10. Self-poisoning
II. Self-shooting
12. Well jumping
13. Others

\section{Causes of deliberate self-harm}

A number of underlying factors are noted by researchers in attempts to explain DSH (Table 3). ${ }^{1,13,16,17}$ An adolescent's peers, family members, and others can interact to lower one's self-esteem, lower one's self-dissatisfaction, and cause dissatisfaction with life. These factors can result in DSH, as well as lead to eventual overt suicide. It is difficult to predict which children or adolescents with DSH will go on to kill themselves, and, thus, all individuals with DSH need careful evaluation and comprehensive intervention.

Nonsuicidal DSH in youth reflects persistent hopelessness and lowered self-esteem, in addition to a potential complex mix of other factors (Table 3 ). The result is the accumulation of inner feelings that are unacceptable and, as the underlying issues (such as stress) continue to build, a personal threshold is crossed in what has been called the "spring" path mechanism, or an uncontrollable self-cutting urge is "switched on" ("switch-path" mechanism). ${ }^{1,18}$ In the proposed "switching on" mechanism, there is the process of dissociation during the act of self-harm and a built-up need for more DSH; the youth with DSH seeks relief from a "terrible state of mind", and the physical hurting releases unbearable feelings, inner tensions, and unacceptable inner pain. ${ }^{11}$ Interviews of youth with DSH reveal that the self-harm allows them to avoid direct or otherwise overwhelming thoughts of suicide, seeks to alert others that they need immediate help, alleviates feelings of self-disgust or self-anger or intense compunction, lowers an overwhelming sense of dissociation, or even releases a major urge to influence others in order to stay alive. ${ }^{1,19,20}$ There may be underlying psychiatric illnesses, such as schizophrenia, personality disorders, major depression, eating disorders, or substance abuse disorders. ${ }^{1,21,22}$ It is also important to note that the type or method of DSH does not in itself allow the clinician to accurately predict the extent, gravity, or degree of the underlying psychopathology that may be present.

Sometimes, very severe states of pathological family dysfunction and communication may be found in pediatric patients with DSH. ${ }^{23}$ Patterns of depersonalization and dissociation may be induced in children and youth subjected to persistent family dysfunction. DSH may result from factors such as severe neglect, early separation from parents, physical or sexual abuse, environment of intense parental rejection and/or criticism, and other evidence of familial chaos that results in youth running away from home, becoming homeless for extended periods or permanently. ${ }^{24,25}$

Individuals with ID can consider thoughts of suicide and even develop overt suicide because of various neurobiological and psychosocial factors. ${ }^{26-29}$ Those with ID may be upset in the face of difficult tasks, an inability to accomplish desired but not achievable goals, effects of psychopharmacologic medications, and other factors. ${ }^{15,30}$

\section{Predictors of adolescent suicide}

Some description of suicide ideation and suicide attempts among adolescents is necessary to help fully understand the complex relationship that exists between DSH and suicide. Salient risk factors for adolescent suicide include a history of past attempts, current suicide ideation and depression, female gender, early pubertal development, alcohol abuse, recent attempt(s) by a friend, low self-esteem, and young and single parents. ${ }^{31,32}$ Suicide is also more prevalent among

Table 2 Prevalence studies in deliberate self-harm behavior

\begin{tabular}{|c|c|c|c|}
\hline Author & Population & Country & Prevalence \\
\hline De Leo ${ }^{5}$ & 3,754 adolescents & Australia & $6.2 \%$ \\
\hline Nixon ${ }^{10}$ & $|4-2|$ years old & Canada & $\begin{array}{l}\text { I7\% DSH; 83\%: self-hitting } \\
\text { cutting, scratching }\end{array}$ \\
\hline Morey ${ }^{8}$ & $3,88 \mathrm{I}$ adolescents & Ireland & $9.1 \% ; 66 \%$ : self-cutting \\
\hline Ystgaard ${ }^{9}$ & 4,060 adolescents & Norway & 6.6\% DSH; 74\%: self-cutting \\
\hline Matsumoto 6 & Teens & Japan & 9.8\%: self-cutting \\
\hline $\mathrm{Li}^{4}$ & Adolescents and adults & Taiwan & $1 \%$ of all injuries; $80 \%$ self-cutting \\
\hline Yates $^{7}$ & $13-18$ years old & USA & $26 \%-37 \%$ : self-cutting \\
\hline
\end{tabular}


Table 3 Deliberate self-harm etiologic factors

I. Abuse
2. Adverse life events
3. Antidepressant medication
4. Bullying and cyberbullying ${ }^{17}$
5. Depression
6. Drug and alcohol use
7. Family and peer conflict and dysfunctionality
8. Impulsivity
9. Low(ered) self-esteem and persistent sense of hopelessness
I0. Poverty
II. Suicidality (ie, suicidal ideation, suicidal plans, suicidal attempt)

already high-risk groups, including adolescents with eating problems, gay, lesbian, and bisexual (GLB) youth, Hispanic youth, and those who have experienced traumatic events. ${ }^{33}$

Among GLB youth, over $40 \%$ have attempted suicide and, contrary to popular belief, those who have openly disclosed their sexual orientation experience higher rates of suicidal thinking. ${ }^{34}$ They often lose friends, experience victimization because of their disclosure, as well as suffer mental health problems and lower levels of self-esteem. ${ }^{34}$ Other studies have noted additional risk factors for adolescent suicidal ideation, including psychological problems, academic challenges, perceiving life as a burden, peer problems, difficulty in planning for the future, poor communication with parents, and an unsupportive home environment. ${ }^{35}$

\section{DSH and risk for suicide}

People with DSH have different underlying etiologic issues; however, all DSH must be taken seriously since it is not possible to predict who will go on to overt suicide now or in the future. ${ }^{36}$ One paramount principle in the study of suicidology is that the risk for overt suicide increases if the underlying factors are not corrected; these factors include chronic problems with parents, and psychiatric disorders. Acts of DSH can occur on a frequent basis, progress to more severe self-mutilation, and evolve into a variety of different harming methods. ${ }^{36}$ Suicide is typically the product of chronic conflicts, but acute reactions can also lead to death, especially in those with impulsivity or the availability of lethal or "unforgiving" methods, such as firearms in the United States. Those who engage in DSH often report a history of childhood sexual abuse, body dissatisfaction, eating disorders, suicide ideation, sexual abuse, physical abuse, physical neglect, emotional abuse, and emotional neglect. ${ }^{37}$ Adolescents who have experienced sexual abuse often engage in DSH, as well as a wide range of other maladaptive behaviors. ${ }^{37}$
The risk of suicide has been noted in some research to increase by $1.7 \%$ at 5 years from the initial attempt, $2.4 \%$ at 10 years, and $3 \%$ at 15 years. ${ }^{38}$ One study noted that about $5 \%$ of individuals with DSH seen in an emergency department kill themselves within 9 years of being seen for the incident of self-harm. ${ }^{3}$ Other research concludes that males with bulimia nervosa $(\mathrm{BN})$ and also males who note analgesia during their self-cutting episodes are at high suicidal risk. ${ }^{39}$ Interestingly, several of the risk factors associated with suicide are also associated with self-harm. These factors include absence of a family confidant, poor parent-adolescent communication, single-parent families, living away from parents, physical abuse, prevalence of suicidal ideation or suicide attempts in mothers, and overall family dysfunction. ${ }^{40}$ Because of this, it is important to distinguish adolescents engaging in acts of NSSI from those who are at risk for a suicide attempt. In a recent study, adolescents who engaged in NSSI had the lowest level risk factors (depressive symptoms, hopelessness, suicidal ideation) and greater levels of self-esteem and parental support. ${ }^{41}$ Unfortunately, there has been an increase in NSSI over the past decade.

DSH may lead to suicide attempts if left untreated. ${ }^{42}$ Risk factors associated with self-harm and suicide include dysfunctional behavior at school, parental psychopathology, relationship difficulties with parents and peers, traumatic life events, aggressive behavior, depression, impulsivity, anxiety, and substance abuse. For adolescents, some of the increase in suicidality and self-harm may be related to the physical and psychological changes that naturally occur during adolescence, as well as social pressure and an increased desire for individuation.

\section{DSH and body dissatisfaction}

Risk factors associated with adolescent body dissatisfaction overlap with many of the risk factors for adolescent self-harm and suicide. Risk factors for adolescent body dissatisfaction include lack of parental support, negative affectivity, restrictive diets, eating pathology, and lack of peer support (marginal). ${ }^{43}$ An interesting note is that body dissatisfaction during early adolescence generally increases for girls and decreases for boys. Specific body dissatisfaction predictors included elevated adiposity (body fat), perceived pressure to be thin, thin-ideal internalization, and social support deficits. ${ }^{44}$

When considered separately, body dissatisfaction risk factors for girls and boys are starkly different. ${ }^{45}$ Weight, greater figure management, and being teased about appearance are generally risk factors for girls, while boys usually 
only experience being teased as a risk factor. General risk factors include puberty, maturational timing, teasing, negative family and peer relations, sociocultural ideals, gender roles, and media influence.

Factors found to protect against body dissatisfaction are positive relationships with parents, spirituality, and participation in extracurricular activities. Adolescent girls and boys can both be dissatisfied with their bodies; however, girls most likely feel overweight while boys feel underweight.

Mass media is often criticized as having a negative impact on body satisfaction. The amount of television watched by adolescents did not correlate with body dissatisfaction or drive for thinness, but type of viewing did, such as watching soap operas, movies, sports, and music videos. ${ }^{46}$ This information supports sociocultural explanations for body dissatisfaction and their influence on eating disorders, thus illustrating an overall shift in societal preference for increasing thinness for females.

\section{Body dissatisfaction and eating disorders}

Body dissatisfaction is one of the most significant risk factors for disordered eating. ${ }^{45}$ One study found that adolescents with clinical eating problems often have a high level of body dissatisfaction, with adolescent females often reporting body dissatisfaction as their being too large while males report dissatisfaction as very close to their actual body mass. ${ }^{47}$ Body dissatisfaction develops as a complex interaction of factors, such as gender, self-esteem, and actual body mass, as well as socially sanctioned restrictive dieting behaviors. With such a complex interaction of factors, future research is needed to integrate psychological, sociocultural, and maturational factors. Additionally, disordered eating is associated with poor academic performance as well as other health-compromising conditions, such as smoking, alcohol and drug use, delinquent behaviors, suicidal ideation, self-harm behaviors, and media influence. ${ }^{48}$

\section{Body dissatisfaction and suicidal behavior}

Two studies specifically address body dissatisfaction and suicidal behavior in adolescents. ${ }^{37,49}$ These studies found that extreme weight control behaviors are associated with suicide ideation and attempts in females but not in males; surprisingly, body mass index (BMI) and body dissatisfaction were not associated with suicidality in males or females. However, other research has found that body dissatisfaction and BMI are associated with suicidality. ${ }^{50}$ These contradictory data support the theory that individual differences must be carefully considered while treating adolescents struggling with body dissatisfaction.

Suicide is one of the leading causes of death among those with eating disorders; thus, it can be postulated that body dissatisfaction is linked to suicide, an association that has already been identified. ${ }^{37,44,49,51}$ The American Association of Suicidology reports that suicide is the leading cause of death in females aged 14-25, with anorexia nervosa (AN) the third leading cause of death for children aged 10-19. ${ }^{51}$ It was also reported that the rate of suicide is 23 times higher in people suffering from $\mathrm{AN}$ and $\mathrm{BN}$; however, those with $\mathrm{BN}$ are at a much lower risk for suicidality than those with AN for unknown reasons. Additional risk factors for those with $\mathrm{AN}$ and $\mathrm{BN}$ include alcohol abuse, mood disorders, cluster B personality disorders, anxiety disorders, hopelessness, impulsivity, perfectionism, low self-directedness, and spiritual acceptance.

\section{Concepts of DSH management}

Unfortunately there is no theoretical model that predicts successful management principles in all those with body dissatisfaction and DSH to prevent eventual suicide. As noted, all such individuals need careful evaluation and comprehensive yet individualized management. Some have suggested that the recurrent motifs of DSH allow statistical analysis, with Hurle models allowing reduction in overt suicide in some patients. ${ }^{52}$ Most clinicians and research suggest that early management intervention is important in preventing or abating malignant DSH, since most persons with DSH do not receive psychiatric interventions. ${ }^{8}$ Pediatric patients can be questioned about suicidality, which includes asking about overt DSH as well as providing examinations that look for skin trauma suggestive of self-cutting or other deliberate self-injury. These adolescents may be involved in various high-risk behaviors, such as illicit drug use and coital activity. Adolescents learn inappropriate and false information regarding suicide on the internet, and clinicians can provide a better educational alternative regarding DSH and suicide.

Traditional methods of management for those with DSH and suicide attempts include psychotherapy, group therapy, school-based interventions, art therapy, possible psychiatric hospitalization, and psychopharmacologic intervention for selective underlying psychiatric disorders (ie, depression, anxiety, psychosis, attention deficit hyperactivity disorder, and other conditions). ${ }^{7}$

Certainly, more research on successful management is critically needed. One meta-analytic review of 
18 studies concluded that current management options do not prevent those with recurrent DSH from completing overt suicide. ${ }^{53}$ However, one should not become too pessimistic in this regard. A positive relationship with a therapist is helpful in providing hope to people as they attempt to improve their coping mechanisms, to lower underlying stress, overcome self-dissatisfaction, and improve communication patterns. ${ }^{18,54}$ Some research suggests utilizing tools of modern technology, such as instant messaging, chat rooms, telephone hotlines, instant e-mail access, and accessing other tools of modern social networks.

Management principles for DSH in persons with ID are traditionally based on attempts at behavior modification, such as response interruption and redirection, extinction, and differential reinforcement; other techniques include providing a preferred item of comfort (toys for example), protection with helmets or gloves, and careful use of selective psychopharmacologic medications (ie, antidepressants, antipsychotics, anticonvulsants, other medications) ${ }^{55-57}$ Clinicians should vigorously seek to understand what the DSH means for the individual person. Antipsychotic medication is usually not beneficial in such situations, because the cause of the DSH in those with ID is usually not psychosis. ${ }^{58,59}$ It is recommended that "punishment-based" techniques be avoided, while the use of restraining or other aggressive methods be studied, because of the ethics of the restraint itself, which must be very judiciously used with minimal harm to this helpless human being. ${ }^{60,61}$

\section{Suggestions for future DSH research}

It is a Herculean task to prognosticate regarding the future of a dilemma such as DSH, since there are so many intangibles involved, including the specific interests of researchers now and in the future, as well as what funding will be available. However, a number of suggestions are now provided for the readers' consideration and reflection. In view of various literature that suggest a protective effect on youth who have "spirituality", 1 it seems worthwhile to explore the effect of this factor on preventing DSH and also on preventing suicide. In addition, it will be critical to study the influences of different family dynamics (ie, parental marital issues and types of parental control) on precipitation of DSH in children and adolescents as they mature from childhood to juvenescence to adulthood. ${ }^{62,63}$ Evidence of DSH behavior in children can signal the potential presence of contributing family dynamics and alert therapists to significant signals to enhance and direct family therapy.
Most of the current research is based on desultory cross-sectional studies that fail to identify factors of causal relationships and their influence on DSH behavior. Thus, a broader, as well as more coherent, direction in research on DSH may be useful. In addition, the research on DSH involves use of quantitative methodology that utilizes post-positivistic approaches; future research should utilize constructionist orientations. ${ }^{1}$ Also, social and medical research should seek to better understand DSH across different communities and cultures to improve the identification and management of this ubiquitous behavior around the world. ${ }^{11}$

Research should also compare various intervention methodologies in both secondary prevention and tertiary prevention programs. ${ }^{1}$ How effective are these various programs and under what circumstances? Secondary prevention research should look at which children and adolescents with early signs of DSH need professional interventions and when this should occur. Most children and adolescents with DSH do not come to the attention of health care providers, and we need improved screening instruments that have researchsupported, enhanced psychometric qualities. ${ }^{8}$ More research on primary prevention programs will most certainly lower a child's or adolescent's risk for DSH and eventual completed suicide. One should never underestimate the short- and long-term value of these children and adolescents having a positive relationship with a clinician in preventing recurrent DSH and suicide. We must seek to augment and strengthen the psychosocial competence and developmental assets in our children, adolescents, and young adults to reduce the initiation and continuance of deliberate self-harm. ${ }^{1}$

\section{Summary}

DSH is a common and yet often clandestine phenomenon in children and adolescents that may become a repetitive pattern and may tragically lead to overt suicide. ${ }^{1,63}$ Etiologic factors include attempts to avoid thoughts of suicide, expression of self-anger or self-disgust, desperate desire to prevent pervasive periods of dissociation, need to influence others (ie, peers, parents), and/or misguided attempts to seek help from others. ${ }^{19,20}$ Overwhelming feelings of self-dissatisfaction are critical issues for many of these persons. Though most children and adolescents with DSH are not at high risk for completion of suicide, it is usually not possible to predict who will eventually kill themselves. ${ }^{64}$ Thus, all acts of DSH should be taken seriously by clinicians and comprehensive management provided. Research should continue to study this complex phenomenon and particularly identify improved methods of prevention - primary, secondary, and tertiary. ${ }^{1,5,65,66}$ 


\section{Disclosure}

The authors report no conflicts of interest in this work.

\section{References}

1. Greydanus DE, Shek D. Deliberate self-harm and suicide in adolescents. Keio J Med. 2009;58(3):144-151.

2. Vajani M, Annest JL, Crosby AE, Alexander JD, Millet LM. Nonfatal and fatal self-harm injuries among children aged 10-14 years - United States and Oregon, 2001-2003. Suicide Life Threat Behav. 2007;37(5): 493-506.

3. Skegg K. Self-harm. Lancet. 2005;366(9495):1471-1483.

4. LiYM. Deliberate self-harm and relationship to alcohol use at an emergency department in eastern Taiwan. Kaohsiung J Med Sci. 2007;23(5): 247-253.

5. De Leo D, Heller TS. Who are the kids who self-harm? An Australian self-report school survey. Med J Australia. 2004;181(3):140-144.

6. Matsumoto T, Imamura F, Chiba Y, Katsumata Y, Kitani M, Takeshima T. Prevalences of lifetime histories of self-cutting and suicidal ideation in Japanese adolescents: differences by age. Psychiatry Clin Neurosci. 2008;62(3):362-364.

7. Yates TM, Tracy AJ, Luthar SS. Nonsuicidal self-injury among "privileged" youths: longitudinal and cross-sectional approaches to developmental process. J Consult Clin Psychol. 2008;76(1):52-62.

8. Morey C, Corcoran P, Arensman E, Perry IJ. The prevalence of selfreported deliberate self-harm in Irish adolescents. BMC Public Health. 2008;8:79.

9. Ystgaard M, Reinholdt NP, Husby J, Mehlum L. Deliberate self-harm in adolescents. Tidsskr Nor Laegeforen. 2003;123(16):2241-2245. Norwegian.

10. Nixon MK, Cloutier P, Jansson SM. Nonsuicidal self-harm in youth: a population-based survey. CMAJ. 2008;178(3):306-312.

11. Madge N, Hewitt A, Hawton K, et al. Deliberate self-harm within an international community sample of young people: comparative findings from the Child and Adolescent Self-harm in Europe (CASE) Study. J Child Psychol Psychiatry. 2008;49(6):667-677.

12. Tenneij NH, Koot HM. Incidence, types and characteristics of aggressive behavior in treatment facilities for adults with mild intellectual disability and severe challenging behavior. $J$ Intellect Disabil Res. 2008;52(Pt 2):114-124.

13. Weissman T. Teenaged, depressed, and treatment resistant: What predicts self-harm? Am J Psychiatry. 2009;166(4):385-387.

14. Rojahn J, Bienstein P. Self-injurious-behavior in children and adolescents with intellectual disabilities. Z Kinder Jugendpsychiatr Psychother. 2007;35(6):411-422. German.

15. Cooper SA, Smiley E, Allan LM, et al. Adults with intellectual disabilities: prevalence, incidence and remission of self-injurious behaviour, and related factors. J Intellect Disabil Res. 2009;53(3):200-216.

16. Hawton K, Rodham K, Evans E, Weatherall R. Deliberate selfharm in adolescents: self-report survey in schools in England. $B M J$. 2002;325(7374):1207-1211.

17. Hay C, Meldrum R. Bullying victimization and adolescent self-harm: testing hypotheses from general strain theory. $J$ Youth Adolesc. 2010;39(5):446-459.

18. Lloyd-Richardson EE, Perrine N, Dierker L, Kelley ML. Characteristics and functions of non-suicidal self-injury in a community sample of adolescents. Psychol Med. 2007;37(8):1183-1192.

19. Klonsky ED, Muehlenkamp JJ. Self-injury: a research review for the practitioner. J Clin Psychol. 2007;63(11):1045-1056.

20. Walsh B. Clinical assessment of self-injury: a practical guide. J Clin Psychol. 2007;63(11):1057-1068.

21. Favaro A, Santonastaso P, Monteleone P, et al. Self-injurious behavior and attempted suicide in purging bulimia nervosa: associations with psychiatric comorbidity. J Affect Disord. 2008;105(1-3):285-289.
22. Csorba J, Dinya E, Plener P, Nagy E, Páli E. Clinical diagnoses, characteristics of risk behavior, differences between suicidal and non-suicidal subgroups of Hungarian adolescent outpatients practising self-injury. Eur Child Adolesc Psychiatry. 2009;18(5):309-320.

23. Portzky G, de Wilde EJ, van Heeringen K. Deliberate self-harm in young people: differences in prevalence and risk factors between the Netherlands and Belgium. Eur Child Adoles Psychiatry. 2008;17(3): 179-186.

24. Murray CD, MacDonald S, Fox J. Body satisfaction, eating disorders and suicide ideation in an Internet sample of self-harmers reporting and not reporting childhood sexual abuse. Psychol Health Med. 2008;13(1):29-42.

25. Yates TM, Carlson EA, Egeland B. A prospective study of child maltreatment and self-injurious behavior in a community sample. Dev Psychopathol. 2008;20(2):651-671.

26. Zilli EA, Hasselmo ME. A model of behavioral treatments for self-mutilation behavior in Lesch-Nyhan syndrome. Neuroreport. 2008;19(4):459-462.

27. Richman DM. Early intervention and prevention of self-injurious behavior exhibited by young children with developmental disabilities. J Intellect Disabil Res. 2008;52(Pt 1):3-17.

28. Merrick J, Merrick E, Morad M, Kandel I. Adolescents with intellectual disability and suicide behavior. Scientific World Journal. 2005;8(5): 724-728.

29. Ernst C, Morton CC, Gusella JF. Self-injurious behaviors in people with and without intellectual delay: implications for the genetics of suicide. Int J Neuropsychopharmacol. 2010;13(4):527-528.

30. Stein MT, Blum NJ, Lukasik MK. Self-injury and mental retardation in a 7-year-old boy. J Dev Behav Pediatr. 2010;31(3 Suppl):S49-S54.

31. Lewinsohn PM, Rohde P, Seeley JR. Psychosocial risk factors for future adolescent suicide attempts. J Consult Clin Psychol. 1994;62(2): 297-305.

32. Wichstrom L. Predictors of adolescent suicide attempts: A nationally representative longitudinal study of Norwegian adolescents. J Am Acad Child Adolesc Psychiatry. 2000;39(5):603-610.

33. Garofalo R, Wolf C, Wissow L, Woods ER, Goodman E. Sexual orientation and risk of suicide attempts among a representative sample of youth. Arch Pediatr Adolesc Med. 1999;153(5):487-493.

34. Hershberger LS, Pilkington NW, D'Augelli AR. Predictors of suicide attempts among gay, lesbian and bisexual youth. J Adolesc Res. 1997;12(4):477-497.

35. Arun P, Chavan B. Stress and suicidal ideas in adolescent students in Chandigarh. Indian J Med Sci. 2009;63(7):281-287.

36. Fortune S, Stewart A, Yadav V, Hawton K. Suicide in adolescents: using life charts to understand the suicidal process. J Affect Disord. 2007;100(1-3):199-210.

37. Murray CS, MacDonald S, Fox J. Body satisfaction, eating disorders, and suicidal ideation in an internet sample of self-harmers reporting and not reporting childhood sexual abuse. Psychol Health Med. 2008;13(1):29-42.

38. Greydanus DE, Calles JL Jr. Suicide in children and adolescents. Prim Care. 2007;34(2):259-273.

39. Matsumoto T, Imamura F, Chiba Y, Katsumata Y, Kitani M, Takeshima T. Analgesia during self-cutting: clinical implications and the association with suicidal ideation. Psychiatry Clin Neurosci. 2008;62(3):355-358.

40. Tulloch AL, Blizzard L, Pinkus Z. Adolescent-parent communication in self-harm. J Adolesc Health. 1997;21(4):267-275.

41. Brausch AM, Gutierrez PM. Differences in non-suicidal self-injury and suicide attempts in adolescents. J Youth Adolesc. 2010;39(3): 233-242.

42. Shin Y, Chung Y, Lim K, Lee Y, Oh E, Cho S. Childhood predictors of deliberate self-harm behavior and suicide ideation in Korean adolescents: a prospective population-based follow-up study. J Korean Med Sci. 2009;24(2):215-222. 
43. Bearman SK, Martinez E, Stice E. The skinny on body dissatisfaction: a longitudinal study of adolescent girls and boys. $J$ Youth Adolesc. 2006;35(2):217-229.

44. Stice $\mathrm{E}$, Whittenton $\mathrm{K}$. Risk factors for body dissatisfaction in adolescent girls: a longitudinal investigation. Dev Psychol. 2002;38(5):669-678.

45. Barker ET, Galambos NL. Body dissatisfaction of adolescent girls and boys: risk and resource factors. J Early Adolesc. 2003;23(2): $141-165$.

46. Tiggemann M, Pickering AS. Role of television in adolescent women's body dissatisfaction and drive for thinness. Int J Eat Disord. 1996;20(2): 199-203.

47. Kostanski M, Gullone E. Adolescent body image dissatisfaction: relationships with self-esteem, anxiety, and depression controlling for body mass. J Child Psychol Psychiatry. 1998;39(2):255-262.

48. Tam C, Ng CF, Yu CM, Young BW. Disordered eating attitudes and behaviors among adolescents in Hong Kong: prevalence and correlates. J Paediatr Child Health. 2007;43(12):811-817.

49. Crow S, Eisenberg ME, Story M, Neumark-Sztainer D. Are body dissatisfaction, eating disturbance, and body mass index predictors of suicidal behavior in adolescents? A longitudinal study. J Consult Clin Psychol. 2008;76(5):887-892.

50. Rodriquez-Cano TL, Beato-Fernandez L, Llario AB. Body dissatisfaction asa predictor of self-reported suicide attempts in adolescents: a Spanish community prospective study. JAdolesc Health. 2005;38(6):684-688.

51. American Association of Suicidology. Suicide and eating disorders. 2010 Available at: http://www.suicidology.org/web/guest/current-research. Accessed December 12, 2010.

52. Bethell J, Rhodes AE, Bondy SJ, Lou WY, Guttmann A. Repeat self-harm: application of hurdle models. Br J Psychiatry. 2010;196:243-244.

53. Crawford MJ, Thomas O, Khan N, Kulinskaya E. Psychosocial interventions following self-harm: systematic review of their efficacy in preventing suicide. Br J Psychiatr. 2007;190:11-17.

54. Fortune S, Sinclair J, Hawton K. Adolescents'views on preventing selfharm: a large community study. Soc Psychciatry Psychiatr Epidemiol. 2008;43(2):96-104.
55. Kahnq S, Iwata BA, Lewin AB. Behavioral treatment of self-injury, 1964 to 2000. Am J Ment Retard. 2002;107(3):212-221.

56. Fortune SA. An examination of cutting and other methods of DSH among children and adolescents presenting to an outpatient psychiatric clinic in New Zealand. Clin Child Psychol Psychiatry. 2006;11(3):407-416.

57. Lang R, Didden R, Machalicek W, et al. Behavioral treatment of chronic skin-picking in individuals with developmental disabilities: a systematic review. Res Dev Disabil. 2010;31(2):304-315.

58. Benson BA, Brooks WT. Aggressive challenging behavior and intellectual disability. Curr Opin Psychiatry. 2008;21(5):454- 458.

59. Tsiouris JA. Pharmacotherapy for aggressive behaviors in persons with intellectual disabilities: treatment or mistreatment? J Intellect Disabil Res. 2010;54(1):1-16.

60. Matson JL, Lovullo SV. A review of behavioral treatments for self-injurious behaviors of persons with autism spectrum disorders. Behav Modif. 2008;32(1):61-76.

61. Jones E, Allen D, Moore K, Phillips B, Lowe K. Restraint and self-injury in people with intellectual disabilities: a review. J Intellect Disabil. 2007;11(1):105-118.

62. Shek DT. A longitudinal study of perceived parental psychological control and psychological well-being in Chinese adolescents in Hong Kong. J Clin Psychol. 2007;63(1):1-22.

63. Chen VC, Tan HK, Cheng AT, et al. Non-fatal repetition of self-harm: population-based prospective cohort study in Taiwan. Br J Psychiatry. 2010;196(1):31-35.

64. Klonsky ED, Olino TM. Identifying clinically distinct subgroups of self-injurers among young adults: a latent class analysis. J Consult Clin Psychol. 2008;76(1):22-27.

65. Greydanus DE, Bhave S, Apple RW. Suicide in children: concepts for clinicians and researchers. Int J Child Adolesc Health. 2010;3(3): $1-11$.

66. Greydanus DE. Treating self-harm in children and adolescents: a Sisyphean complex conundrum for the clinician. Psychiatric Times. 2011;28(2):32-37.
Journal of Multidisciplinary Healthcare

\section{Publish your work in this journal}

The Journal of Multidisciplinary Healthcare is an international, peerreviewed open-access journal that aims to represent and publish research in healthcare areas delivered by practitioners of different disciplines. This includes studies and reviews conducted by multidisciplinary teams as well as research which evaluates the results or conduct of such teams or

\section{Dovepress}

healthcare processes in general. The journal covers a wide range of areas and welcomes submission from practitioners at all levels, from all over the world. The manuscript management system is completely online and includes a very quick and fair peer-review system. Visit http://www.dovepress.com/testimonials.php to read real quotes from published authors. 